\title{
The Office of Real Soon Now, Western Pilot (Projectors In Offices Project)
}

S.L. Uselton

\section{March 11, 2002}

U.S. Department of Energy

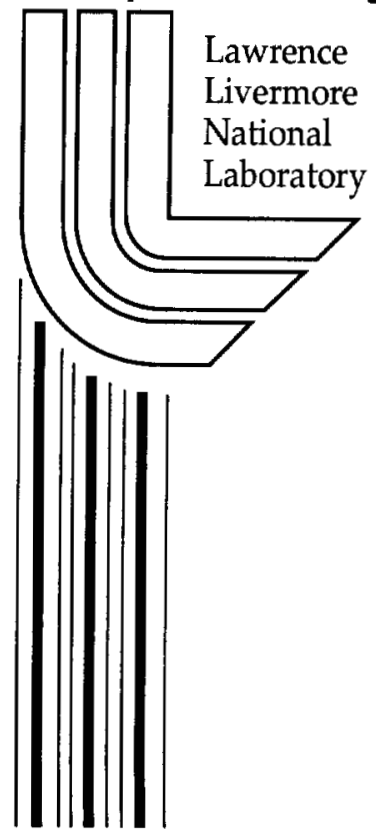




\section{DISCLAIMER}

This document was prepared as an account of work sponsored by an agency of the United States Government. Neither the United States Government nor the University of California nor any of their employees, makes any warranty, express or implied, or assumes any legal liability or responsibility for the accuracy, completeness, or usefulness of any information, apparatus, product, or process disclosed, or represents that its use would not infringe privately owned rights. Reference herein to any specific commercial product, process, or service by trade name, trademark, manufacturer, or otherwise, does not necessarily constitute or imply its endorsement, recommendation, or favoring by the United States Government or the University of California. The views and opinions of authors expressed herein do not necessarily state or reflect those of the United States Government or the University of California, and shall not be used for advertising or product endorsement purposes.

This work was performed under the auspices of the U. S. Department of Energy by the University of California, Lawrence Livermore National Laboratory under Contract No. W-7405-Eng-48.

This report has been reproduced directly from the best available copy.

Available electronically at http://www.doc.gov/bridge

Available for a processing fee to U.S. Department of Energy

And its contractors in paper from

U.S. Department of Energy

Office of Scientific and Technical Information

P.O. Box 62

Oak Ridge, TN 37831-0062

Telephone: (865) 576-8401

Facsimile: (865) 576-5728

E-mail: reports@adonis.osti.gov

Available for the sale to the public from

U.S. Department of Commerce

National Technical Information Service

5285 Port Royal Road

Springfield, VA 22161

Telephone: (800) 553-6847

Facsimile: (703) 605-6900

E-mail: orders@ntis.fedworld.gov

Online ordering: http://www.ntis.gov/ordering.htm

OR

Lawrence Livermore National Laboratory

Technical Information Department's Digital Library

http://www.llnl.gov/tid/Library.html 


\title{
"The Office of Real Soon Now, Western Pilot" (Projectors in Offices Project)
}

\author{
Samuel P. Uselton \\ Center for Applied Scientific Computing \\ Lawrence Livermore National Laboratory
}

\section{Introduction}

The ASCI VIEWS program at Lawrence Livermore National Laboratory (LLNL) has been investigating a variety of display technologies, motivated by the large size, high resolution and complexity of some data sets that ASCI users explore and analyze. The purpose of this report is to describe the design, deployment and initial user reactions to one display system. The inspiration for the system comes from a similar experimental deployment at the University of North Carolina at Chapel Hill (UNC), one of the VIEWS program's academic partners. The display system features the use of multiple projectors in individual offices creating oversized displays to replace standard monitors. Some discussion on alternative multi-projector display systems provides context for this description.The VIEWS program began exploring the possibilities of alternative displays by building large, tiled displays and supporting the development of extremely high-pixel density LCD panels [ASCI]. The same considerations have led to partnerships with several groups of researchers working on various aspects of multiprojector display systems including groups at UNC, Stanford University, Princeton University, the University of Utah, Argonne National Lab, and the two NSF supercomputer centers, NCSA and SDSC.

This report is divided into eight sections. The following section describes the background for the development of this multi-projector display system, including brief descriptions of other largeformat and high-resolution display projects, and provides some LLNL motivations for exploring further. Section III covers the evolution of the design intended specifically for LLNL and explains some of the factors that influenced the decisions made. Section IV provides a detailed description of the two installations, including materials and resources involved. After a few weeks of experience with the systems, the users were interviewed and their reactions and comments are summarized in Section V. Conclusions, recommendations, and a short list of references complete this report.

\section{Background and Motivation}

Interactive computer graphics is a demanding computational application. The appearance of smooth motion requires that the scene being rendered must be redrawn at least 30 times per second. Interactive manipulation of objects in the scene requires the effect of the user's actions to be apparent in less than one tenth of a second. The more complicated the scene, the more difficult it is to meet these requirements. During the 1990s computer graphics hardware has become capable of interactive display of much more sophisticated scenes than before.At the same time, some data sets have become so complex that they have more detail than can be displayed on a single screen. Several research groups began exploring strategies for expanding display 
possibilities. The use of multiple video projectors in place of monitors led to the development of CAVEs [CAVE] (CAVE Automatic Virtual Environment) and PowerWalls [PowerWall]. Both of these systems use a collection of projectors in a rear-projection arrangement to display more of a scene than is possible on a single display.

A PowerWall is essentially a single display screen with an array of projectors sending images that cover the screen and show coordinated views of a scene. A CAVE puts screens as four, five or even six faces of a box surrounding the user, with a single projector for each face, also displaying coordinated output of a single scene. Often these systems are combined with head tracking and stereo display equipment to provide exciting, virtual environment experiences. One of the main drawbacks to the use of these systems, however, is the infrastructure required to support them. Computing the images for multiple views of a scene at interactive rates requires large computer systems and specialized software. In addition to the space, power and cooling requirements of these computers, these display systems also have substantial physical requirements, particularly space. As a result, these installations are expensive and fairly rare. Therefore they are generally shared among a sizable user community, which places constraints on individual users. A typical user must reserve the resources (the display and the computational resources) in advance and go to wherever the display is installed. Users travel from "down the hall" to 50 or 100 miles to gain access to such systems for relatively brief periods. Effective use of this time means that the installation is supported by a staff who assist users, not only during use of the system, but also in preparing for this use. The need for staff increases the operating costs substantially. As prices for projectors and computer graphics capacity started to drop over the past few years, a few research groups began exploring the possibilities of more modest systems, which could be built in larger numbers and be made more easily available. As users increased their familiarity, support staff could be reduced. Unfortunately, the extra floor space required by rear-projection systems was still an issue and has hampered this proliferation. Hence, the UNC group decided to experiment with front projection.

The front-projection effort is known as "The Office of the Future" Project [OOTF Project]. The goal of this project is described via a vision of what an office could be if projectors were so cheap and plentiful that all light in an office could be from projectors and all surfaces in the office could be projection surfaces. Front projection is assumed so additional floor space is not required, allowing the option of retrofitting current offices. The usual disadvantage of frontprojection systems is that the user gets between the projector and the screen, and the resulting shadow covers exactly what was attracting the user's interest. The UNC vision avoids this problem by having multiple projectors aimed at all surfaces and by compensating for shadows by making the image from other projectors brighter. Cameras are used to provide feedback for shadow compensation and other image overlap issues, as well as user tracking to support apparent depth of field, parallax and view-dependent update of the images. One of the key concepts sometimes overlooked in this vision is the premise that most offices would be equipped with such systems, so they are always accessible, designed for every day use. [OOTF1], [OOTF2]

After elaborating a research agenda based on a wide variety of problems that must be overcome to make the Office of the Future feasible, some in the UNC group asked "What can we put in offices now?" In 1998 Gary Bishop of UNC replaced his monitor with two video projectors 
hung from the ceiling of his office and put a label by the door reading "The Office of Real Soon Now" [GB OORSN]. His colleagues liked the results and emulated it, with adaptations for individual situations [GW OORSN]. There are currently five faculty members at UNC using projectors in place of monitors. They have worked with interested parties at MIT, the University of Utah, Carnegie Mellon University, the University of Kentucky and Brown University, to develop additional installations, and they arranged a temporary installation at NSF headquarters, which was removed when the user left NSF. Since projectors are still relatively expensive, the office installations have only a small number of projectors, generally two or three, and use inexpensive models, limiting resolution and features. The Office of the Future would require many more projectors, maybe twenty or thirty, to support double coverage of most surfaces in an office. The projectors in current use are connected to Windows PCs or Apple computers that are used for daily activities, such as reading email and writing papers and programs. Even though the faculty involved are predominantly computer graphics researchers, these displays are used predominantly for text-oriented purposes [OORSN].

In 1998 LLNL installed a display screen 8 feet high and 16 feet wide that was driven by a large SGI system feeding 15 projectors. The resolution provided is $6400 \times 3072$ or a total of almost 20 million pixels [LLNL Wall]. In order to see a particular feature with the same detail on a workstation monitor, the software would have to zoom in so close that most of the visual context, provided by the surrounding data, would be off screen. The drawback of using this facility, however, is that it requires reserving both the physical room and the eight SGI IR2 graphics "pipes" needed to drive the display. Since the room is a conference room shared by several organizations, scheduling such time can be difficult. As a next step, LLNL installed an eightprojector display wall in a space designed specifically for data analysis. This system and the facility containing it are better designed for "drop in" use, but the users must still travel to the facility (from other floors of the building or other buildings at LLNL) and may have to compete with other users for the required computer resources. A third system, constructed from six individual "display cubes," was installed in CASC's main seminar room. This system has visible mullions separating the individual projected images, but it has better color consistency than the other walls and requires much less staff support to keep in adjustment. Anecdotal evidence indicates that users like both the large size and the high resolution provided by these three displays.

The ASCI VIEWS program has supported the investigation and development of other very high resolution display technologies. One example is IBM's high resolution LCD panel. The three ASCI labs now have research prototypes of this panel, which packs approximately nine million pixels into a frame only slightly larger than a standard workstation LCD panel. The quality of the display is excellent, but many users report that they must enlarge their content in order to see it clearly. This display also requires substantial resources to update the screen at interactive rates; it uses four standard connectors to route the signals into the panel. Another example is the construction of frames to hold two and four standard LCD displays and use them as single displays. Although bigger, these displays have large mullions through the center. They also require significant resources to update. One question raised by these contrasting approaches concerns the relative value of size and pixel count. Such a question can best be addressed in the context of specific tasks, but the answer may well be different for different tasks. 
A team from UNC led by Henry Fuchs was awarded a DOE subcontract for work on large-scale tiled displays through the Data and Visualization Corridor activity. The technical contacts for this work were in the ASCI VIEWS program due to common interests. This collaboration led to the suggestion of installing an "Office of Real Soon Now" at LLNL. There was much interest at LLNL in having many more, large and high resolution display systems onsite for visualization of large, complex data sets. Designing, developing, and deploying an office based system at LLNL would provide opportunities to adapt the system to specific uses and to evaluate such systems for a range of tasks beyond those typically found at UNC. Having this type of display system onsite rather than in North Carolina also meant that many more people would be able to examine the system in person. The installation can also be viewed as an experiment in transferring technology from an academic subcontractor to the Lab.

\section{Alternatives Considered: Design and Implementation}

Initial conversations with the UNC group identified desired properties of a system for use at LLNL based on the use of projectors in standard offices. The goals were for the system to exceed the previous UNC versions in resolution, to be run via Unix, and to support interactive visualization of simulation data better than the workstations and monitors replaced by the displays. Rear projection was considered only briefly. All rear-projection systems proposed either required large amounts of floor space behind the screen or required the design and precise construction of a complex enclosure with mirrors to fold the path of light from the projector to the screen. Abutting images were selected rather than overlapping images, both to preserve the largest possible pixel count and to avoid complexities in blending overlapped images. This decision does impose a greater sensitivity to image alignment problems.

As projectors were becoming more widely available, smaller, and cheaper, the first concrete design suggestion specified four "commodity" (relatively inexpensive, standard model) projectors in a two-by-two array. Such a system would provide a combined resolution of $2048 \mathrm{x}$ 1536 pixels. However, there were two main obstacles to the design and deployment of such a system: (1) producing the images required a suitable host or hosts, and possibly some new software to enable the four images to be treated as a single display; and (2) custom mounting of the system to deploy the geometric and mechanical arrangements required for the projectors implied significant design and construction activities. We decided to install two systems in order to provide better feedback about the project, as well as to spread the load of "tourists" that was expected to follow successful deployment. Two volunteers, Gary Kerbel and Milo Dorr, both from CASC, stepped forward. Both have offices in a property protection area, which is convenient for others at the lab to view and assess the installations. Both Milo and Gary spend part of their time examining the visualizations of simulation output, the most important task justifying improved office displays.

Many systems using four or more projectors have been built using large host systems, typically from SGI but also Hewlett-Packard (HP) among others. Each of these systems is to be hosted by a single, user class workstation. The desire to treat the four images as a single display, even for interactive visualization of three-dimensional data, ruled out the use of a cluster of machines. By the summer of 2000 , several computer systems were available that supported the installation of 
multiple graphics boards, and software was available to treat the result as a single display for $2 \mathrm{D}$ purposes. But using them for 3D meant relying upon software execution of OpenGL instructions rather than using hardware acceleration. Unfortunately, the performance without hardware acceleration is insufficient. While there have been PC cards supporting two video outputs for quite some time, there were rumors that a four output card might appear by the end of 2000 . It was thought that with the Linux drivers being funded by VIEWS, this card could enable a viable solution. However, no such card appeared. In the spring of 2001, Sun Microsystems demonstrated a system that supported four graphics cards as a single display with hardwareaccelerated Java3D graphics instructions. The system required an Ultra 60 workstation, which is substantially more than the typical Ultra 10 office workstation.

Arranging the projectors also proved difficult. For the best image quality, the projectors should be as far apart as the centers of their images. This distance depends upon the size of the images, which is determined by the distance from the projectors to the screen and the lenses of the projectors. Reducing the spacing between projectors without reducing the image size means that the projectors are not projecting orthogonal to the screen. The result is a distortion of the image in which the edge of the image farther from the projector is larger, distorting the rectangle into a trapezoid. This distortion is known as "keystone distortion" or "keystoning." Some projectors have a feature to correct keystoning in one axis, but not in both axes. Some projectors, especially those designed for table-top use, are built for off-center projection so that the bottom edge of the image is level with the projector and the top edge is much higher. This can be thought of as a very specific keystone correction. If these projectors can be used in other orientations (rotated 90 or 180 degrees), then the spacing between projectors may be reduced. Image keystoning also exacerbates the alignment difficulties for abutting the images, since adjacent edges may no longer be parallel. Another difficulty is that the four pyramids of light from the projectors to the screen fill a large volume of space in an office, making it difficult to find a place for users to sit without casting shadows onto the screen.

As a result of these difficulties, several alternatives were explored. A single projector is easily supported by a workstation and avoids the geometric problems outlined above. However, commodity projectors have a maximum resolution of $1024 \times 768$ pixels, which is less than typical user's workstations at $1280 \times 1024$ pixels. Higher resolution projectors were available, but they were much more expensive (typically more than $\$ 20,000$ ) and much heavier (e.g., 25 pounds) making mounting more difficult. They also tended to be hot and noisy and therefore inappropriate for office use.

Arrangements for two commodity projectors had already been explored by UNC, and the Linux drivers could make it possible to drive them from PC graphics cards. The resolution as used at UNC was $2048 \times 768$ pixels. We decided that if the projectors could be operated while rotated on their side, then $1536 \times 1024$ pixels was available. The smaller (vertical) dimension would then match the users' current workstations (at 1024) and provide around $25 \%$ more for the horizontal dimension (at 1536 vs 1280 pixels). This increase seems very small for the amount of work involved. So we decided to proceed with a system based on the Sun Ultra 60 and four commodity projectors, and a work order was placed to increase the power to the two offices selected so that the Sun system and the four projectors did not overload the existing circuits. 
Then, in early summer 2001, three companies announced $1280 \times 1024$ pixel resolution projectors that were substantially smaller, lighter, quieter, cooler, brighter, and less expensive than any previously available. Two such projectors have about $80 \%$ of the pixels of the four commodity projectors previously identified, and they can be driven from PC graphics cards-including accelerated 3D - via the Linux drivers produced for the VIEWS subcontract. Standard orientation yields $2560 \times 1024$ pixel resolution; $2048 \times 1280$ pixel resolution would be available if the projectors could be operated in a rotated orientation. This option became the primary plan, assuming these projectors were actually available and not just "announced."

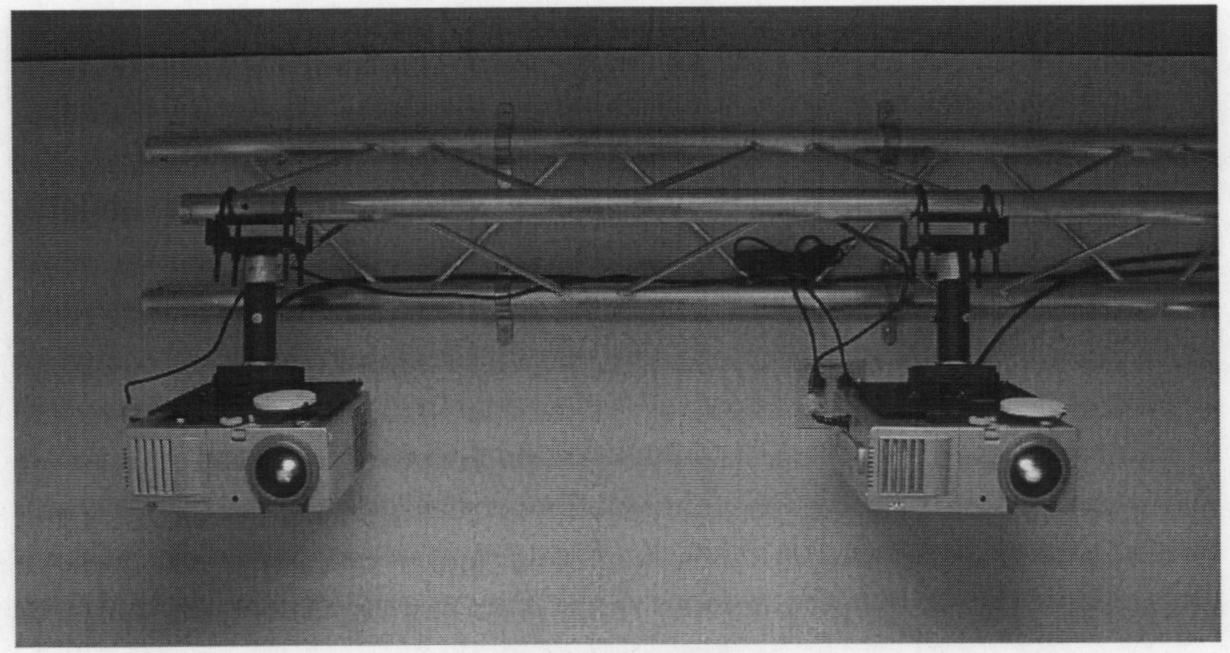

Figure 1a. Two projectors suspended from an Opti truss by Chief mounting hardware.

\section{Systems as Implemented}

The systems were installed in two offices, and while the components used were basically the same, the installation details varied. There are two JVC model DLA-DS1 projectors in each office [JVC DLA-DS1]. Each projector has $1280 \times 1024$ pixel resolution, weighs less than 15 pounds, provides 1300 lumens, and had a list price of $\$ 9000$. These projectors also provide a digital keystone correction feature. The host computers selected were Dell Precision 530 workstations with two processors and one gigabyte of memory, running RedHat Linux version 7.1. They have been equipped with VisionTek graphics boards [VisionTek] based on the Nvidia GeForce2 MX graphics chip [Nvidia]. These graphics boards supply one standard VGA output and one DVI-I output, which can be configured using the TwinView mode to look like a single display to the X server. The projectors are attached to an Opti Trilite truss [Opti] by projectormounting hardware from Chief Manufacturing [Chief Mfg]. The truss consists of three parallel tubes of two inches in diameter, rigidly fixed in a triangle, twelve inches on a side, by smaller structural elements. The truss was bolted to the wall a little more than seven feet above the floor by LLNL staff familiar with relevant structural and safety issues. Figure 1a shows a pair of projectors and the truss. Although a similar truss made from one-inch diameter tubes is available from Opti, and would have been strong enough for our project, the largest triangle made this way would have been nine inches on a side. The chosen twelve-inch triangle was needed to provide enough distance from the wall for the projectors and their connectors. In each office one sheet of 
GatorFoam, 4 feet by 8 feet and one-quarter-inch thick, was initially used as the projection screen, as shown in Figure $1 \mathrm{~b}$.

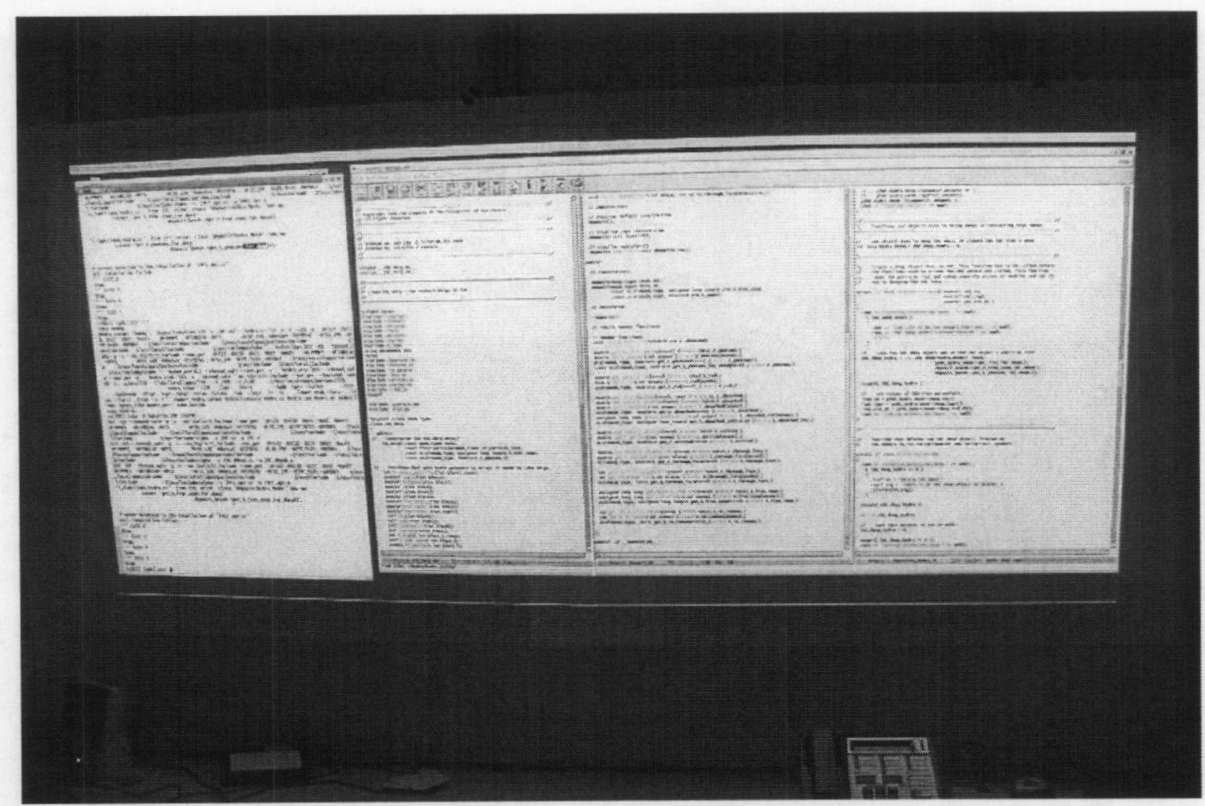

Figure 1b. Images from two projectors on GatorFoam screen.

While the basic elements are identical in both offices, there are several differences in the installations based on variations in the office spaces and the users themselves. Scott Miller and Sam Uselton installed the computer and projectors in Gary Kerbel's office on November 30, 2001. Gary has a relatively small, roughly square, office with windows along the north wall, and a door and pillar on the south wall. The truss and projectors were mounted on the west wall and the projection screen propped up on the desk against the east wall. Gary was present during the installation and gave feedback as we worked. The most significant feedback was that he strongly preferred the image size to be made as small as possible because the images would be brighter (same lumens, less area). The image size was planned to be 8 feet by 3 feet total, but after adjusting as much as the projectors permitted, it is more like 80 inches by 30 inches. At that time Gary still had a monitor and a large table supporting it in front of the window, which limited where Gary could put his chair. We attempted to center the display on the position where Gary typically sat given the furniture in his office. As a result, the projectors were shifted south, toward the door. In fact, we had to improvise a doorstop to protect one of the projectors. Figure 2 shows the proximity of the door to the projector when the door was against this doorstop. 


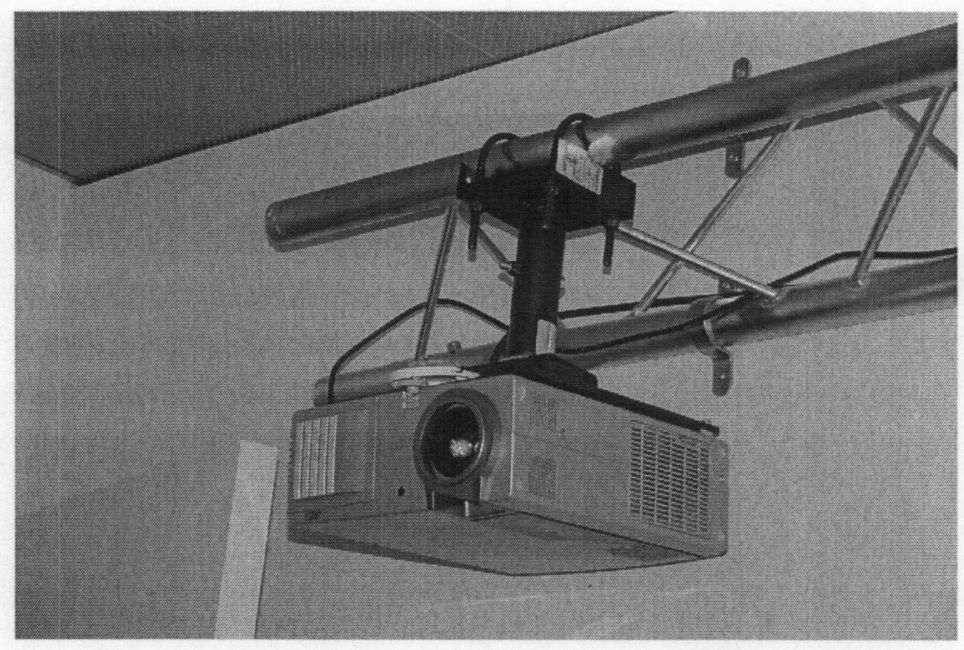

Figure 2 Proximity between projector and door.

Gary works while seated in a special chair that gives him a partially reclining posture. This unusual seating meant that he would like to have the display fairly high. This height means that the top of the screen would be much further from Gary than the bottom, if the screen is absolutely vertical. UNC recommends tilting the screen to make it more perpendicular to the projectors rather than using keystone correction, because their experience with keystone correction affected the image quality. However, in this situation Gary preferred to tilt the screen in the opposite direction, making it more perpendicular to his view, and more oblique to the projection direction. The keystone correction provided by these projectors is used at its maximum setting.

In conjunction with this chair, Gary uses his keyboard and pointing device on a lapboard that rests across the arms of the chair, as shown in Figure 3. For ergonomic reasons, he prefers a trackball over a mouse. Wires to the keyboard and trackball were awkward, particularly during the operation of removing the lapboard so he could get in and out of the chair. Hence, we acquired a wireless keyboard and trackball for him to use. To complete the picture, Gary usually works with the lights off and the blinds partially deployed so that image contrast is improved.

Figure 3 Gary Kerbel's work environment, before the wireless keyboard. 


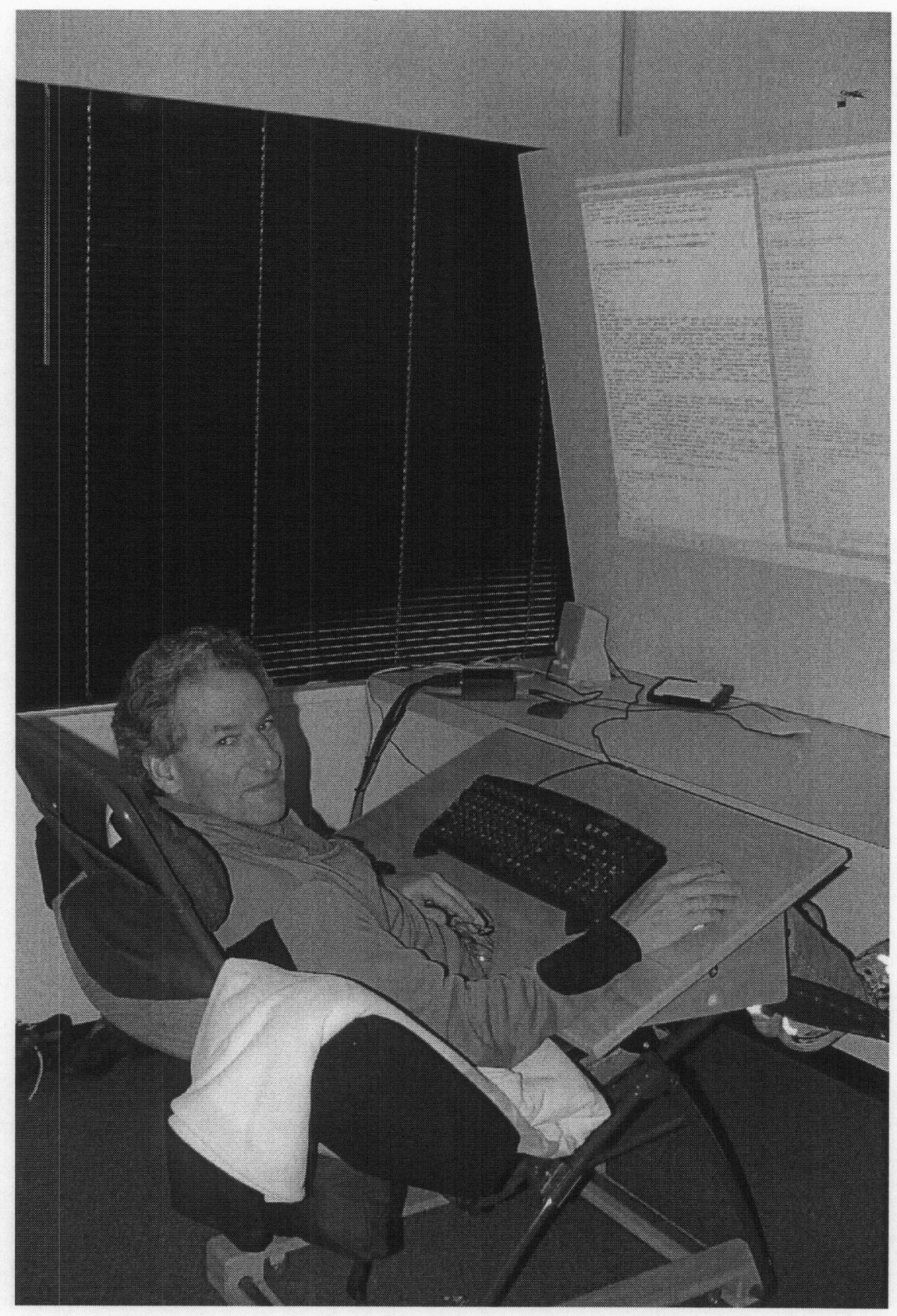

Our second volunteer, Milo Dorr, has a more rectangular office, longer in the east-west dimension, with windows on the north and west sides. Scott Miller and Sam Uselton installed Milo's projectors and computer on December 12, 2001. His truss is mounted above the windows on the north wall, as seen in Figure 4a. There is sufficient room between a pillar and the west wall for the screen along the south wall, shown in Figure 4b. Milo sits conventionally and asked to have the large display as low and as vertical as possible. He also said he would prefer brighter images, so we went to the small end of the image size adjustment immediately. A small, wheeled table was found that was large enough to accomodate Milo's keyboard and mouse. While this seemed adequate, we decided to acquire a wireless keyboard and mouse for him as well. Milo 
tried working with the lights out, but finds he has less eye fatigue at days end if he has more ambient light, so he typically works with half of his lights on.

Figure 4a - Milo Dorr's work environment.

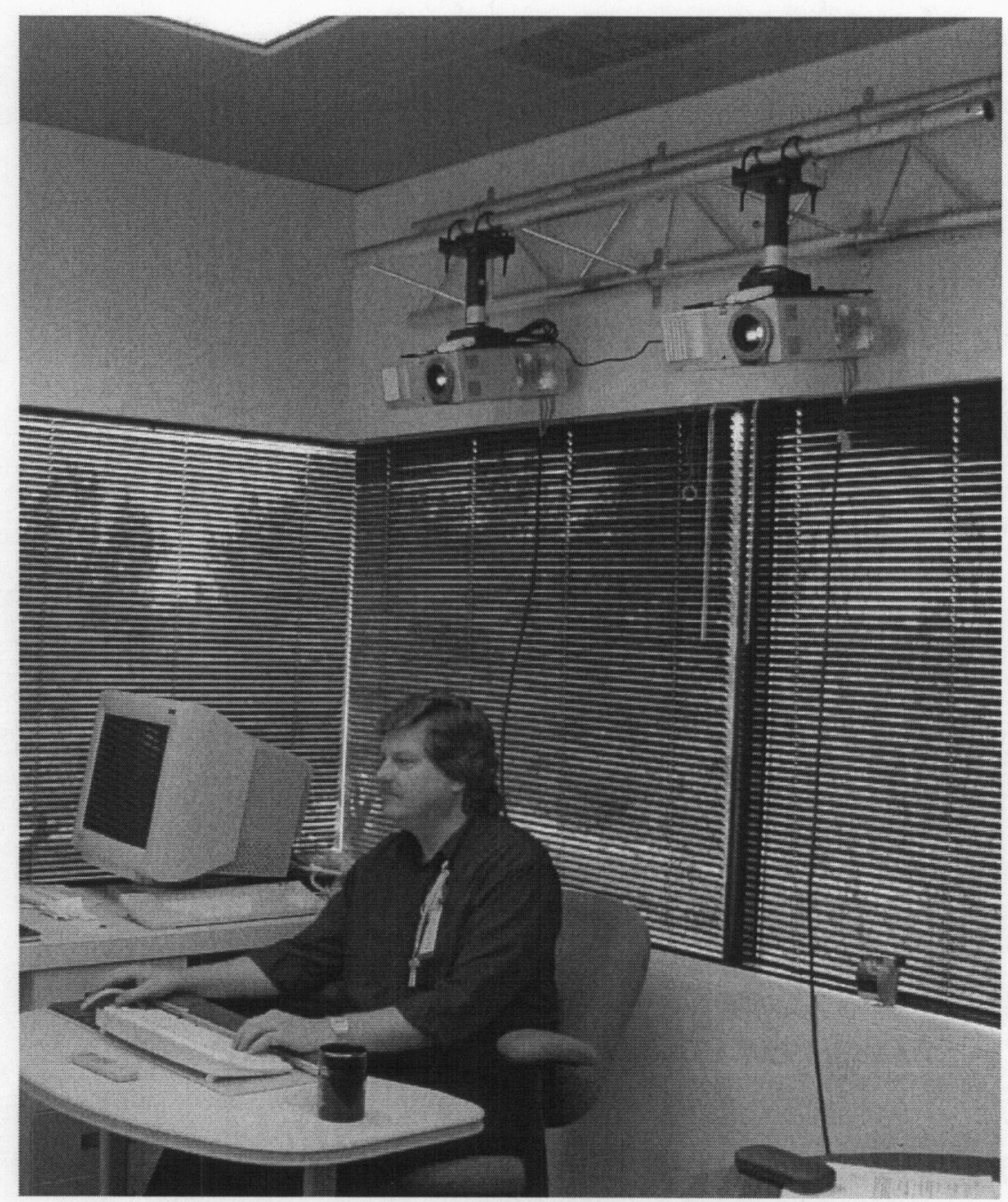

Figure 4b. Milo's GatorFoam screen (before trimming and mounting). 


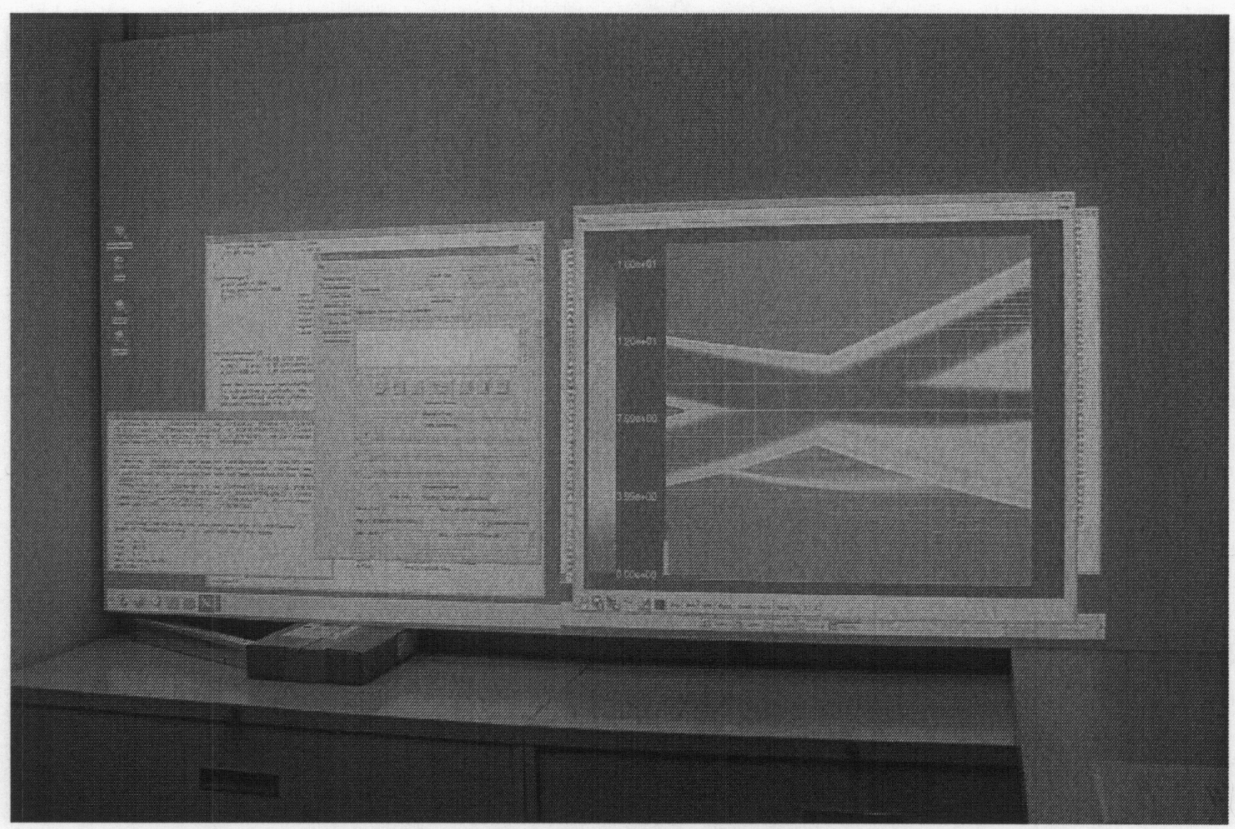

\section{Experience}

Between the times of the first and second installations, several minor issues with the first installation were identified. Most were corrected immediately. The two issues that required the most effort to diagnose and correct involved the stability of the projectors. There was a large (but infrequent) wobble as a result of play in the mounting hardware attaching the projector to the truss. There was also a smaller, high frequency vibration of one projector that was more constant. This vibration was eventually diagnosed as originating in the truss itself, because the projector in question was attached at the end, beyond any of the small structural elements. While preparing for the second installation, Scott discovered a better arrangement of the Chief hardware which eliminated the possibility of the wobble. Once these difficulties were diagnosed, we advised Gary that we would reinstall his projectors, correcting the problems and re-centering the image in the larger space available after the extra table and monitor were removed. This shift would also

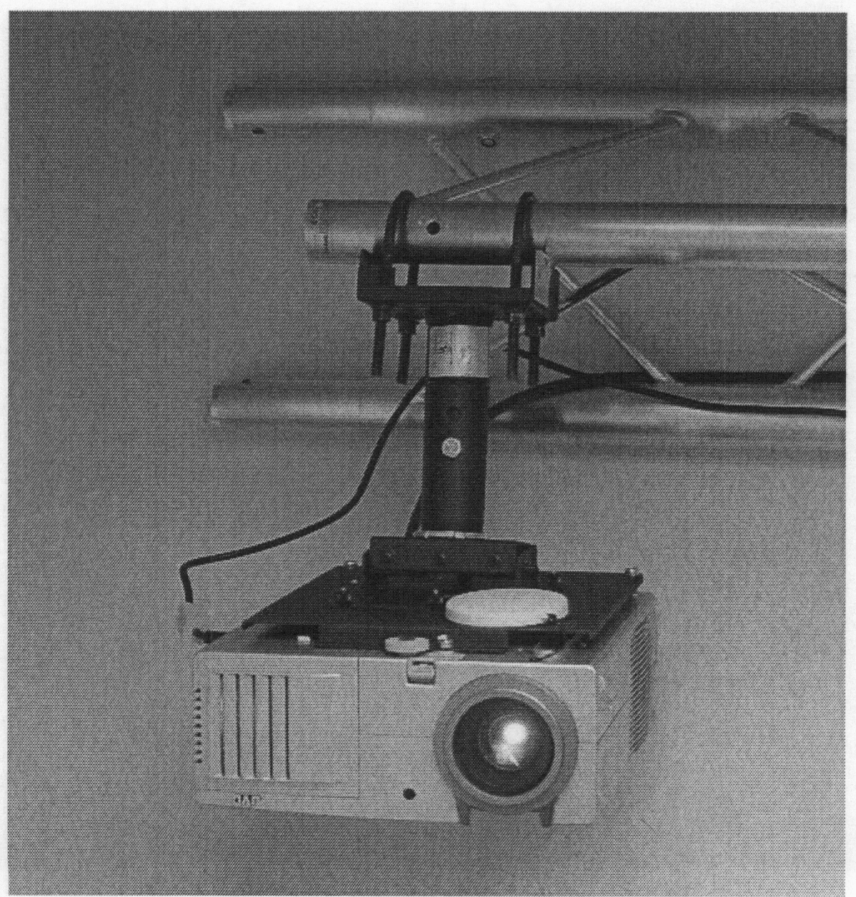


avoid the need for the improvised doorstop. The following day, when Sam went to Gary to schedule these changes, he discovered that Gary had already implemented the changes himself.

Figure 5a. Vibrating projector mounted too near the end of the truss.

Figure 5b. More stable projector after being moved.

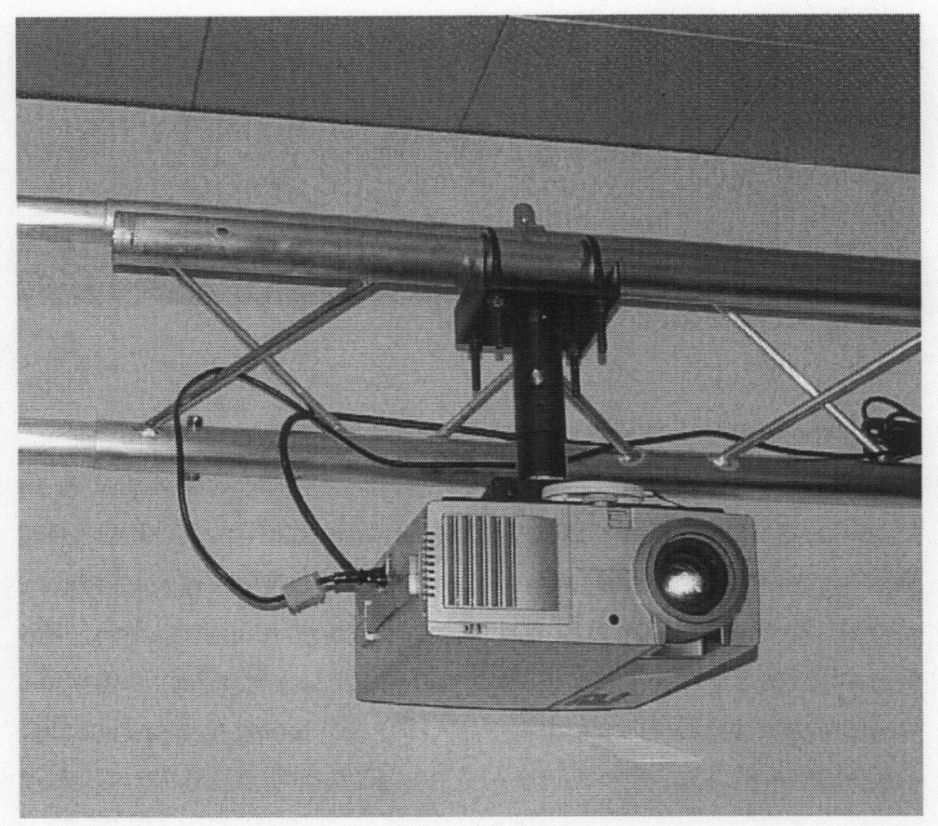

The GatorFoam screens were obtained from the Technical Information Department (TID) at LLNL, who use such materials frequently. They were asked to mount the screens in the offices once the proper locations were determined. Since the image size was smaller than originally planned, we asked them to trim the screens before mounting them. The screens were trimmed to 3 feet by 7 feet and given rounded corners. Gary had accomplished the forward tilt using materials at hand. TID re-installed it after trimming, and added a slight curve, which helps with the image distortion that results from the variation in distance between the projector and different parts of the screen. Even so, these projectors are making full use of the digital keystone correction available.

Milo's screen was mounted with a slight tilt backwards because there is an electrical outlet in use behind the lower portion of the screen. This outlet is rarely accessed, but the power strip plugged into it is essential. Tilt in this direction is recommended by the UNC team to reduce the need for keystone correction, but this tilt is less than their suggestion. The screens are mounted with velcro so they can be removed easily if need arises. 
There seemed to be some image quality issues that were specific to the DVI-I output of the graphics card, which uses a converter to drive the same type of VGA projector input as the other output of the graphics card. The problem made reading text difficult, especially letters with thin vertical portions, suggesting a video bandwidth issue. Piecing together information from the VisionTek web-site, the XFree86 installation guide, and our collaborators at UNC led to the use of the $\mathrm{X}$ configuration to reduce the refresh rate. At about $10 \%$ below the bandwidth indicated by the VisionTek specifications, this problem was significantly reduced. A noticeable color difference between the output channels remains.

Both users switched from Unix to Linux systems. Timing was planned so that Milo could transition to Linux at about the same time as others working with him on the ALPS project. This transition was relatively smooth for both users. Gary is accustomed to working on a variety of systems (Sun, HP, SGI) and at one point asked about a multi-way switch so he could use one projector as the display for any of these machines. His Windows PC was connected to a projector via the 2-way switch he already had. Access to the other machines is now via remote logins from windows on the Linux system, which is at least as convenient as switching the projector. Milo's keyboard and mouse were connected to his Windows machine in the same way, but we have been unable to get the projector to switch between the two sources. Milo has a monitor for use with his Windows laptop, but he has begun using a Citrix server provided by CASC for Windows functions and likes it at least as well as switching between his local Linux and Windows machines. Support for these Linux workstations is provided by Dustin Komjack and Dave Provine, the same team supporting Linux in the rest of CASC . Support for the projection systems is being provided by the Information Management and Graphics Group, which also support the tiled display systems at LLNL.

Marlene Sandberg, the Ergonomics Coordinator for the Computation Directorate, was already working with Gary before the project and has demonstrated substantial interest in the use of projectors as alternative displays. She has also brought several others to see the systems, including an optometrist employed by the Lab. She is particularly interested in participating in any further user evaluation work.

The two users were interviewed to get their assessment of these display systems. Gary Kerbel was interviewed on February 13, 2002. Milo Dorr was interviewed on February 14, 2002. Marlene Sandberg participated in Gary's interview but was not available for Milo's. Since there are only two users, the interviews were fairly informal. They were first asked to comment with little specific guidance, then were asked more specific questions. Many of the comments were the same from both users. They liked the increase in the amount of information that can be displayed at once. They both commented on how the large format was especially valuable for use by small groups. The wireless keyboards and pointers were not only convenient for the users, but also facilitated sharing control during collaboration sessions. There were little or no problems blocking the projectors. The projector fan noise is noticeable, but not objectionable. In fact, one user said that it helped block distracting noises from the hall. The heat from the projectors is also noticeable, but both users found it pleasant. Both users would like the images to be brighter or higher contrast, and higher resolution. Both users noted color differences between the two 
projectors, as shown in Figure 6, and both users often place window boundaries along the color discontinuity, removing the distraction.

Figure 6. Color mismatch between images, may be projectors, graphics card or both.

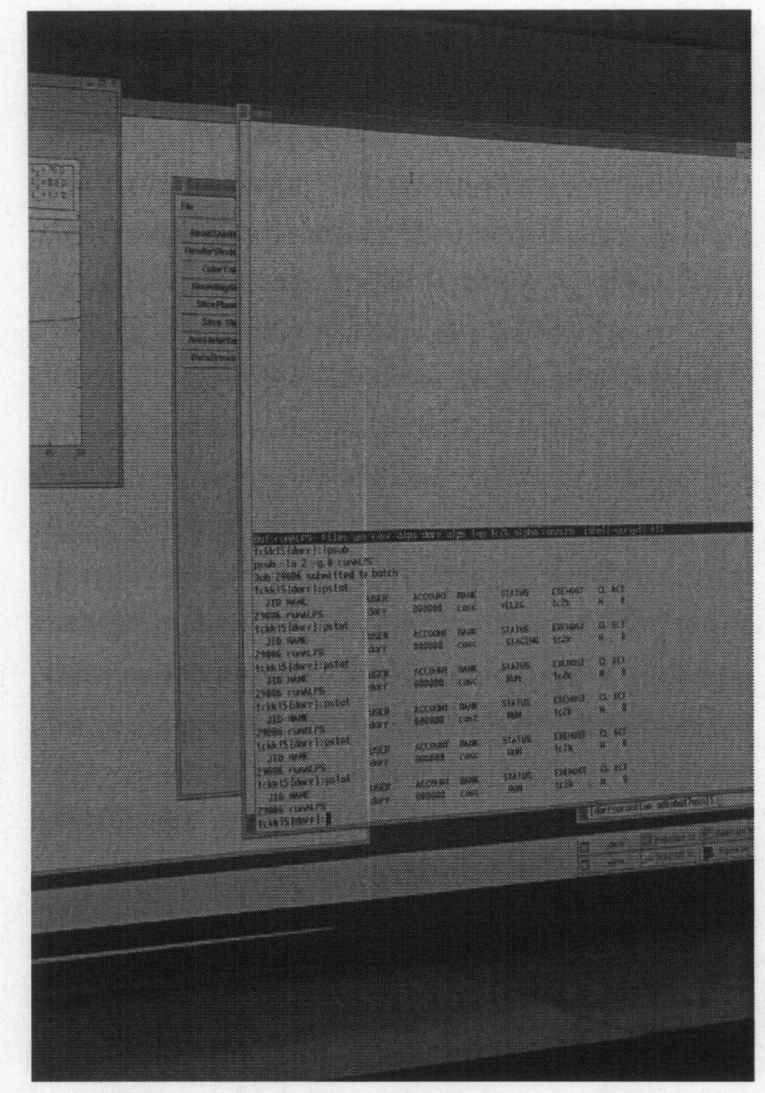

Each user also made unique comments. Gary commented on vibrations resulting from things like doors closing down the hall. He also said that it was too difficult to get the two images to stay precisely aligned, but that he found the usual one sixteenth of an inch mismatch acceptable. We installed panels used for shaping stage lights, called "flags," in Gary's office to address a brighter area in the center, where light from the projector "leaking around the image" overlapped the other projector's image. The bright overlap region is shown before the flag installation in Figure $7 \mathrm{a}$, and after the flag installation in Figure $7 \mathrm{~b}$. Figure 8 shows the flags and projectors from below. The flags reduced but did not totally eliminate this bright area. The edges of the area were also blurred, further reducing the impact. He said he has used the display primarily for textoriented work, although he did display some images as part of the process of getting the new version of AVS Express needed to run under this version of Linux. This was not enough to provide much feedback for that kind of use. He expects to be doing much more work with visualization and images beginning in April. In spite of some of the problems, Gary is very enthusiastic about using the system and "would never want to go back." 


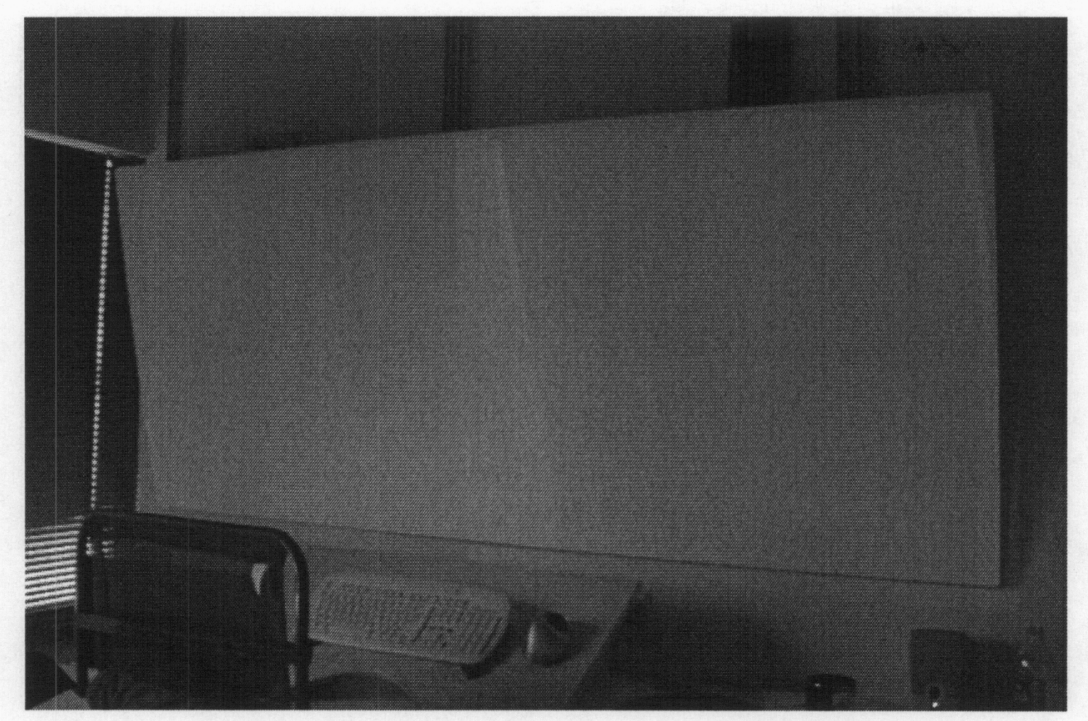

Figure 7a. The bright central wedge is from light "outside" the intended images.

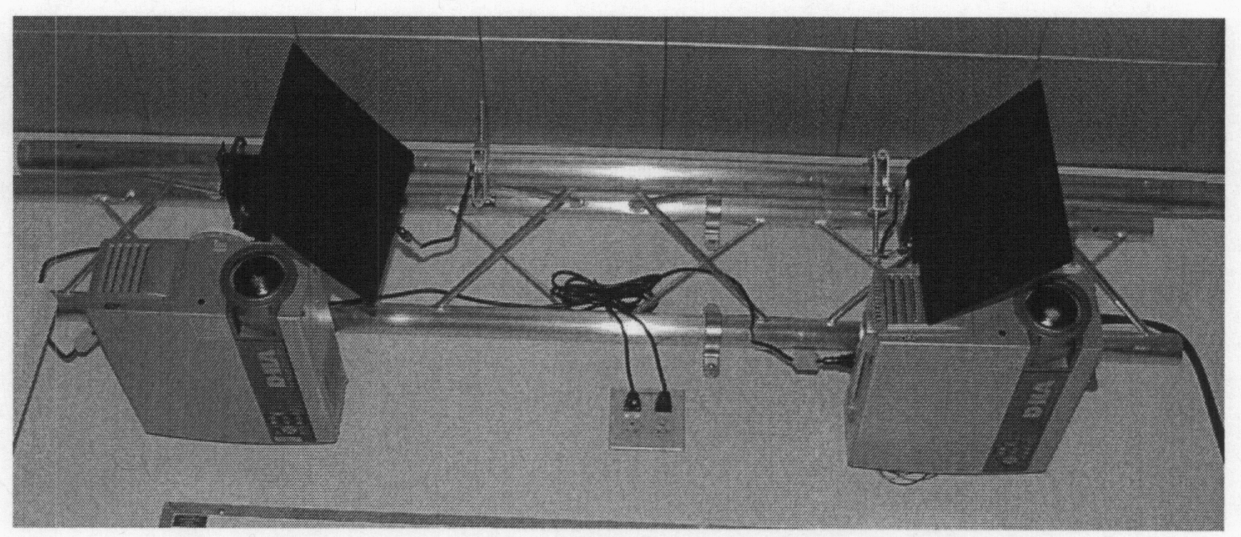

Figure 8. A view from below showing the position of flags relative to the projectors. 


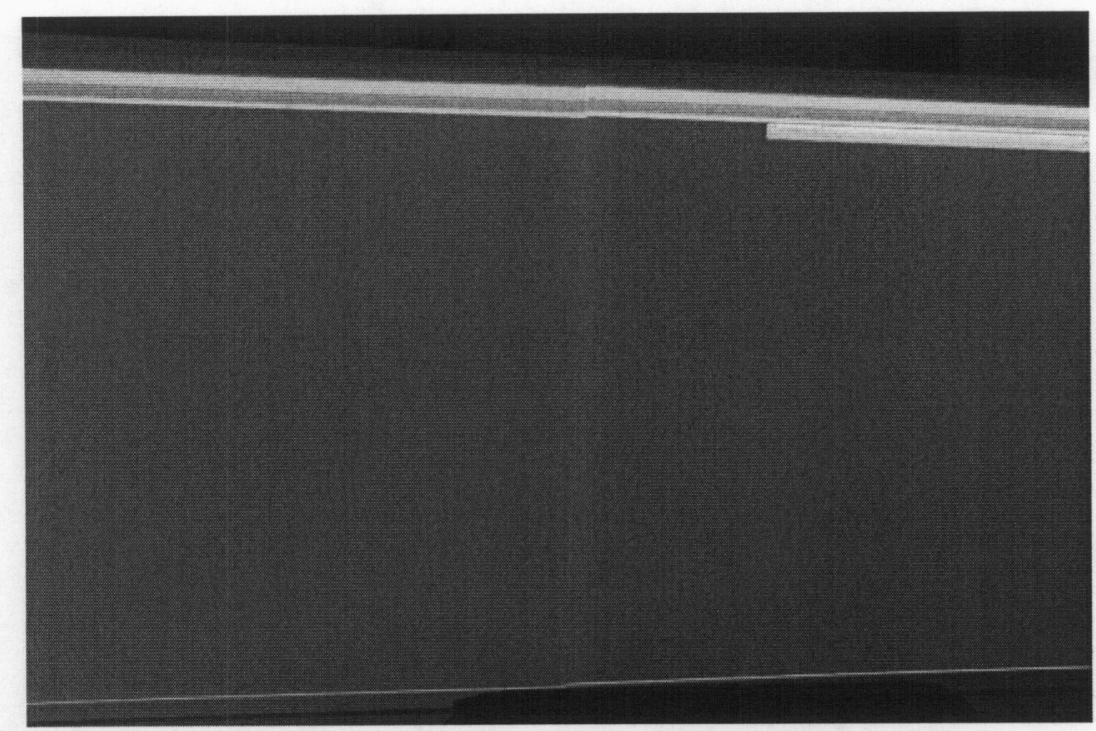

Figure $7 \mathbf{b}$. The impact of the central overlap is reduced by the flags.

We have been unable to get a projector in Milo's office to switch between two input sources via a KBM switch. There seems to be some signal strength or quality issue, which will be investigated further after shorter cables are installed. Milo has begun using the Citrix server rather than switching to the Windows machine in his office, which seems to work well. He also observes intermittent increases and decreases of brightness, which he finds distracting. These changes are relatively uniform across one projector's image, can stay brighter for time periods from fractions of a second to several seconds, and happen on either projector, frequently but unpredictably. In addition to the contrast, he would also like the image to be sharper. Milo's overall assessment was more cautious than Gary's; he said it was "too soon to tell" whether he really likes it or not.

On March 6, Gary reported intermittent intensity variation ("stepping") like what Milo had already been experiencing. By coincidence, the sales representative who sold us the JVC projectors visited LLNL that afternoon, and stopped by to see these installations. She observed the intensity "stepping", the color variation between images, and substantial color variation within a single image as well. She is forwarding this information to JVC for their advice.

\section{Conclusions \& Recommendations}

The projector-based display systems installed at LLNL use higher resolution projectors than any in office use at UNC. Our users seem to sit closer to the screens; the image subtends a larger view angle than the monitor which was replaced. The goal at UNC is for the image of a single projector to subtend the same angle as the monitor replaced. We have not been as meticulous in positioning the screens perpendicular to the center of projection; we chose to orient them for the users' best view and use the projector's features to correct the image distortion. The UNC web site advises against this strategy, but our newer model, high resolution projectors accomplish this correction better than expected. 
Even though the systems are not perfect, user reaction is generally positive, one enthusiastically and the other cautiously. This evaluation should be considered preliminary. Additional experience, particularly with image-oriented applications, is needed. Both image brightness and projector heat should be checked during the summer. Longer usage will also give more information on maintenance and system stability.

The truss system was easy to install and works quite well to provide flexibility in spacing the projectors precisely for a chosen image size. Mounting it on a structural wall results in less vibration than when mounted on the interior wall. Ceiling-mounted systems may be preferable in some situations, and less conspicuous wall mounting may be possible with smaller projectors and more experience in predicting positions. The Chief mounting hardware works quite well (once properly installed) and allows easy removal of the projector from the truss as well as precise directional positioning.

The projectors are good but could be better. At 1300 lumens, they are bright enough for a darkened room, but images lose much contrast when ambient light is present. More "temperature" adjustments might allow better color matching between projectors. Even higher resolution would be nice. Wireless keyboards and pointers are convenient and inexpensive, and enhance collaborative interactions. Installation of wireless equipment in restricted areas is not currently supported; some accommodation should be explored.

The conversion to Linux workstations was not an issue. Feedback is that these machines are faster than the workstations replaced, and have more memory, and both improvements have been appreciated. There are some issues with the graphics cards. The bandwidth of the analog signal from the DVI-I output is lower than one would like, and there seems to be a substantial difference between that signal and the signal from the other output. GeForce2 is also an older graphics chip, so some aspects of the graphics performance do not match what Linux users with only a single monitor and GeForce 3 based graphics cards see. There are no cards using the GeForce 3 chip which support the MX features, but the recently announced GeForce 4 does support these features. Once the Nvidia Linux driver supports the GeForce4 based cards, then an upgrade seems useful, particularly if a card can be found that uses two identical video outputs.

At $\$ 8,000$ each (discounted from the $\$ 9000$ list price) these projectors are substantially more expensive than monitors, making the whole system relatively expensive. However, the systems as deployed cost less than initially anticipated, and less than graphics workstations of only a few years ago. And the prices continue to drop rapidly, while resolution and features improve. Reaction by the users seems sufficiently positive to continue the evaluation and include projectors in the list of possibilities for advanced office displays as the prices become more reasonable. Two or even three projectors in a single row are fairly easy to position and align. Higher resolution projectors seem preferable to attempting multiple rows of projectors in an office.

\section{Acknowledgements}

As with most projects, many people have contributed to these results. The ASCI VIEWS program funded this project, and many in that project provided some support. Randy Frank's 
knowledge of current and future PC graphics technology was particularly helpful. Bob Howe helped us learn about LLNL procurement processes. Scott Miller participated in the installation of the projectors and screens from planning through image tuning. Ross Gaunt provided extensive projector expertise and contacts. Linda Doyle not only allowed these strange installations in her building, but arranged for a variety of work from office repainting to running new power circuits. Cindy Bottero took the photographs and Willie Webb brought them online. Several people involved in the UNC Office of Real Soon Now were very helpful, particularly Herman Towles, Greg Welch, Henry Fuchs, and Gary Bishop. Finally, Milo Dorr and Gary Kerbel agreed to try these systems and have been ideal early adopters, proactive and responsive, and tolerant of tourists in their offices.

\section{References}

\section{Web pages:}

[PowerWall]

University of Minnesota http://www.lcse.umn.edu/research/powerwall/powerwall.html

[OOTF Project]

The Office of the Future Project: http://www.cs.unc.edu/ raskar/Office/

\section{[GB OORSN]}

Gary Bishop's Office of Real Soon Now: http://www.cs.unc.edu/ gb/office.htm

\section{[GW OORSN]}

Greg Welch's Office of Real Soon Now: http://www.cs.unc.edu/ welch/oorsn.html

\section{[Opti]}

http://www.optikinetics.com/IndexA.htm

\section{[Chief Mfg]}

http://www.chiefmfg.com/default.asp

[JVC DLA-DS1]

http://pro.jvc.com/prof/Attributes/features.jsp?tree=\&searchModel=\&model_id=MDL101273

[VisionTek]

http://www.visiontek.com/

[Nvidia]

http://www.nvidia.com/

\section{Publications:}

\section{[ASCI]}

Heerman, P.D. "First-Generation ASCI Production Visualization Environment," IEEE Computer Graphics \& Applications, vol 19, no 5, 1999, pp 66-71. 
[CAVE]

Cruz-Neira, C., D. Sandin, T. DeFanti, R. Kenyon and J.C. Hart, "The CAVE: Audio Visual Experience Automatic Virtual Environment," CACM vol 35, no 6, June 1992, pp 64-72.

[LLNL walls]

Schikore, D.S., R.A. Fischer, R. Frank, R. Gaunt, J. Hobson, and B. Whitlock, "High-Resolution Multiprojector Display Walls,", " IEEE Computer Graphics \& Applications, vol 20, no 4, 2000, pp 38-44.

[OOTF1]

Raskar, Ramesh, Greg Welch, Matt Cutts, Adam Lake, Lev Stesin, and Henry Fuchs, "The Office of the Future: A Unified Approach to Image-Based Modeling and Spatially Immersive Displays", Computer Graphics. M. F. Cohen. Orlando, FL, USA (July 19 - 24, 1998), ACM Press, Addison-Wesley: 179-188.

[OOTF2]

Welch, Greg, Henry Fuchs, Ramesh Raskar, Michael Brown, and Herman Towles, "Projected Imagery In Your Office in the Future," IEEE Computer Graphics and Applications, July/August 2000: 62-67.

[OORSN]

Bishop, Gary, and Greg Welch, "Working in the Office of 'Real Soon Now", IEEE Computer Graphics and Applications, July/August 2000: 76-78. 